\title{
Breast cancer in Latin America and the Caribbean
}

\author{
Sylvia C. Robles ${ }^{1}$ and Eleni Galanis ${ }^{2}$
}

ABSTRACT As recently as two decades ago breast cancer was not a significant public health concern in Latin America and the Caribbean (LAC). However, mortality rates from breast cancer have been increasing for at least 40 years in most LAC countries. Socioeconomic development and consequent changes in reproductive behaviors over the past 50 years are thought to have contributed to the increased risk of breast cancer. Socioeconomic development has also increased women's health awareness and therefore the demand for quality services. In industrialized countries, screening and widely available, high-quality treatment protocols are being implemented as the main strategy for breast cancer control. Studies show that out of three available screening methods (mammography, clinical breast examination, and breast self-examination), only mammography for women 50-69 years of age has been effective at reducing mortality, and has done so by an estimated $23 \%$. While there is much controversy about the benefits and cost-effectiveness of mammography screening for women aged 40-49, some countries, including Australia, the United States of America, and four European nations, recommend that physicians assess the need for it on an individual basis. A survey that we conducted of LAC countries shows that most of their breast cancer screening policies are not justified by available scientific evidence. Moreover, as seen by relatively high mortality/incidence ratios, breast cancer cases are not being adequately managed in many LAC countries. Before further developing screening programs, these countries need to evaluate the feasibility of designing and implementing appropriate treatment guidelines and providing wide access to diagnostic and treatment services. Given the relevance of breast cancer in Latin America and the Caribbean today, it is crucial that both women and health care providers have access to up-to-date information on which to base their decisions.

Key words Breast cancer, women's health, screening, Latin America, Caribbean.

Only two decades ago breast cancer was not on the public health agenda in the countries of Latin America and the

\footnotetext{
Pan American Health Organization, Program on Non-Communicable Diseases, Washington, D.C., United States of America. Send correspondence to: Sylvia C. Robles, Pan American Health Organization, Program on Non-Communicable Diseases, 525 23rd Street. N.W., Washington, D.C. 20037, United States of America; telephone: (202) 9743306; fax: (202) 974-3625; e-mail: roblessy@paho. org

2 University of Toronto, Community Medicine Residency Program, Toronto, Ontario, Canada.
}

Caribbean (LAC). However, epidemiological and demographic transitions, which have accelerated in these nations since the 1960s, have led to increased exposure to risk factors for cancer in general, and for breast cancer in particular. Fertility rates and infant mortality have decreased, leading to a proportionately higher population of adults and elders. Also, urbanization is increasing rapidly in most LAC countries, from $24 \%$ in the 1950 s to a projected $80 \%$ in the year 2010 (1).
These and other social changes, such as higher levels of education and the entry of women into the paid workforce, have increased women's health awareness and understanding and consequently their demand for quality health services.

Industrialized countries have responded to the breast cancer epidemic by making resources available for research and evaluation of screening and treatment practices. At the same time, lobbying from organized non- 
governmental groups has made the problem of breast cancer more visible. The new body of scientific evidence, the wide dissemination of research findings, and, most of all, increased public awareness are now affecting policy in developing countries. However, LAC countries do not have the same social environment, epidemiological profile, or availability of services that more developed countries do. Therefore, in order to evaluate the feasibility of breast cancer control programs in Latin America and the Caribbean, it is important to assess: 1) the burden of breast cancer in each country, 2) the accessibility to health care services for all population groups in those countries with high breast cancer incidence, and 3) whether early detection of breast cancer is feasible, given competing priorities for scarce resources.

To address some of these issues, we examined breast cancer mortality in Latin America and the Caribbean and compared it with the mortality levels in Canada and the United States of America. We also evaluated the arguments for developing breast cancer screening programs, given the current scientific evidence.

\section{METHODOLOGY}

The analysis is primarily based on data from three sources: vital statistics records, published cancer registry data, and information available from the Pan American Health Organization (PAHO) concerning disease prevention and control programs, health expenditures, and health service organizations in Region of the Americas.

The Pan American Health Organization (PAHO) collects cause-specific mortality data from each of its Member States and assesses the preliminary data from the countries for quality and completeness. A detailed description of the process can be found elsewhere (2), including data-quality indicators for each of the nations and data availability by year. In this report, we included only countries for which registrations of deaths were considered to be at least $85 \%$ complete, where at least 100 breast cancer deaths were reported in the latest year, and where reporting was consistent over the years. We also included the Commonwealth of Puerto Rico in our study (in this study, the figures for the United States do not include the data on Puerto Rico).

For our study we calculated the mortality rates for women beginning at age 25 and truncated at age 74 , in line with the methodology of the International Agency for Research on Cancer (IARC) $(3,4)$. For age groups over 74 , the LAC data were of poor quality. We calculated mortality trends in three-year age-standardized moving averages. When data were missing for a country in any given year, we calculated a two-year average and standardized by age according to the World Population (3). If data were missing for two or more years consecutively, we did not calculate the rate for that time period.

We calculated mortality/incidence ratios for countries where data were available. To calculate mortality rates we used data from PAHO, and we used incidence rates from the population-based cancer registries as published in the IARC's Cancer incidence in five continents (3). In three of the countries-Argentina, Colombia, and Uruguay-incidence data were not available for the entire country, but only for a single urban area in each of them (Concordia, Cali, and Montevideo, respectively). In spite of the fact that the incidence and mortality data for Argentina, Colombia, and Uruguay represent only part of the population, we included Cali because it has the longest-standing population-based cancer registry in Latin America and has reliable data, and Concordia and Montevideo because their data are the only incidence data available for these two countries, which show the highest breast cancer incidence rates in Latin America. Both incidence and mortality rates are representative of the country as a whole for Canada, Costa Rica, Puerto Rico (commonwealth), and the United States. To compare incidence and total fertility rates we used data from cancer registries, which, with the exception of the countries mentioned above, represent cities rather than the entire country.

In order to study the association between total fertility rate (TFR) and breast cancer incidence, we obtained TFRs from PAHO data (2), and we derived age-standardized breast cancer incidence rates from the International Agency for Research on Cancer, as described above.

Using a mail survey, we surveyed the countries of Latin America and the Caribbean that are PAHO Members and that have more than 300000 inhabitants. Sent to the ministry of health $(\mathrm{MOH})$ of each of those nations, the survey form asked about breast cancer control initiatives and, in particular, about the "official" $\mathrm{MOH}$ recommendations regarding screening for breast cancer. In order to confirm or clarify the $\mathrm{MOH}$-provided information, we obtained additional documentation concerning the approved policies. We made no attempt to inquire about breast cancer control programs outside the public sector or to assess whether the recommendations were in fact followed. We knew in advance that only Uruguay had made efforts to implement an organized breast cancer screening program; other countries recommend screening but it is opportunistic. We carried out the initial data collection in July 1998. With the countries that in 1998 reported having screening policies, we reconfirmed that information in April 2000.

\section{RESULTS}

At the population level, fertility rates are inversely associated with the incidence of breast cancer and can thus be a proxy indicator for the stage of demographic and epidemiologic transition of a given country. In the Americas the incidence of breast cancer increases as there is a decrease in the total fertility rate (average number of children a woman has in her reproductive years), as shown in Figure 1. Indeed, Canadian women have one of the lowest fertility rates (1.6 children 
FIGURE 1. Age-standardized breast cancer incidence rate vs. total fertility rate for selected countries and cities of the Americas, plus Puerto Rico, 1997

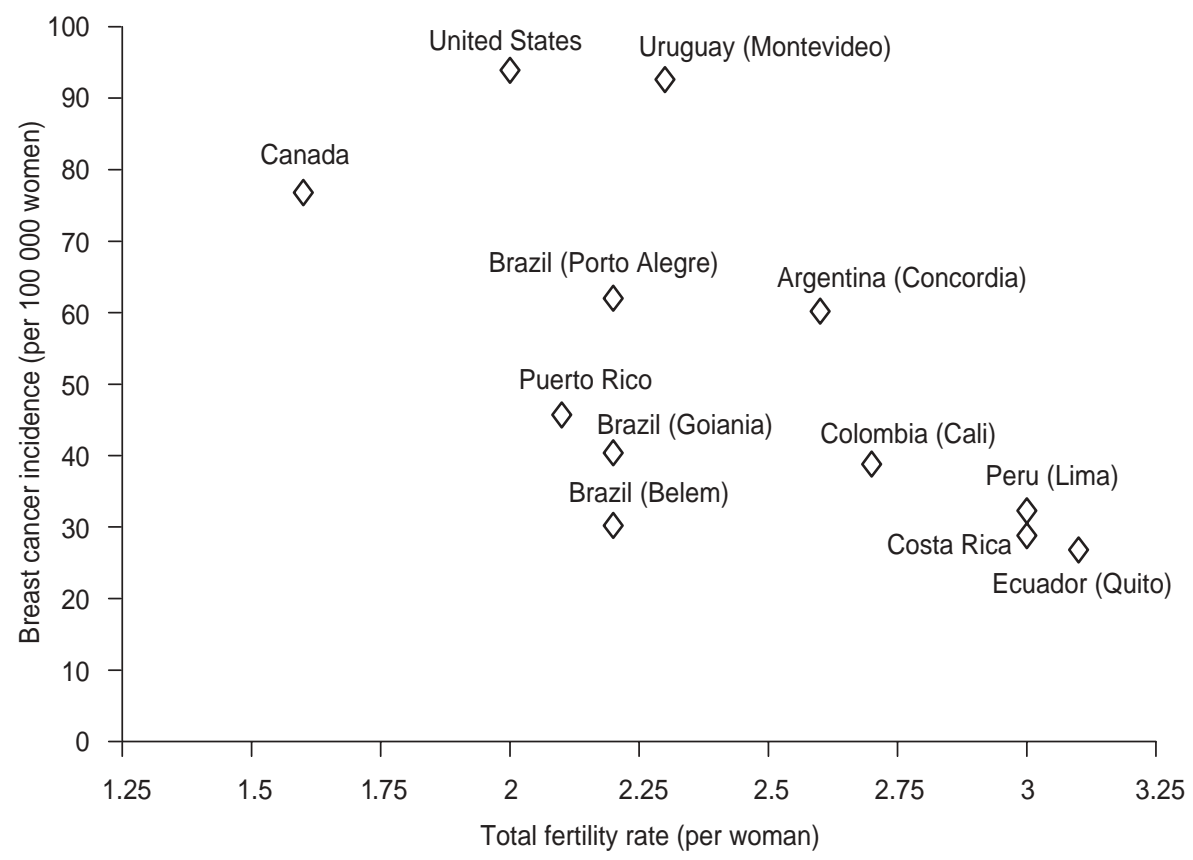

per woman) and one of the highest annual breast cancer incidence rates (76.9 per 100000 women). On the other hand, Ecuadorian women have an average of 3.1 children and an incidence rate for breast cancer of 26.8 per 100000 , one of the lowest documented in the Americas.

Table 1 shows age-standardized breast cancer mortality rates per 100000 women aged 25-74 years old for selected countries in the Americas as well as Puerto Rico. Breast cancer mortality in the Americas is by far the highest in Uruguay, where it reached an all-time-high age-standardized mortality rate of 44.6 per 100000 women aged 25-74 years in 1996-1998. Uruguay is followed by Canada, the United States, Argentina, and Trinidad and Tobago, whose rates ranged between 32 and 37 breast cancer deaths per 100000 women per year for the 1996-1998 period. During this same time period Cuban, Puerto Rican, and Chilean women exhibited rates between 20 and 27 per 100 000. Women in Costa Rica and Venezuela had breast cancer mortality rates somewhat below 20 per 100 000. Finally,
Colombia and Mexico reported the lowest rates in 1996-1998 for this group of countries, at 15.2 and 15.1 deaths from breast cancer per 100000 women per year, respectively. 1966-1998

a The figures for the United States of America do not include Puerto Rico.

b The ellipsis symbol (...) indicates that data were not available.
Figure 2 depicts an increase in mortality rates from 1960 to 1994 in countries (and Puerto Rico) where breast cancer mortality was relatively low. Of the six entities shown there, only Chile seems to have arrested its upward trend, even reporting a slight decrease in breast cancer mortality in recent years. Mexico and Colombia have shown a gradual increase in their rates, whereas Costa Rica, Puerto Rico, and Venezuela have demonstrated a more rapid rate of increase in mortality since the 1980s.

Among the countries with high breast cancer mortality rates, the most striking phenomenon is the downward trend in Canada and the United States, where mortality rates began falling in 1987 and 1990, respectively, as shown in Figure 3. Cuba and Argentina have shown constant mortality rates since the mid-1970s. Breast cancer mortality rates have been slowly rising in Uruguay, whose rates have been the highest in Latin America and the Caribbean since the 1960s.

Table 2 presents the mortality/incidence $(\mathrm{M} / \mathrm{I})$ ratios that we calculated for selected countries, plus Puerto Rico. The United States had the lowest

TABLE 1. Three-year moving average age-standardized breast cancer mortality rate per 100000 women aged 25-74, for selected countries of the Americas, plus Puerto Rico,

\begin{tabular}{lcccc}
\hline Subregion/Country & $1966-1968$ & $1976-1978$ & $1986-1988$ & $1996-1998$ \\
\hline North America & & & & \\
$\quad$ Canada & 41.9 & 40.0 & 40.5 & 37.0 \\
$\quad$ Mexico & 7.6 & 10.2 & 13.5 & 15.1 \\
$\quad$ United States & & 39.3 & 39.4 & 36.9 \\
Southern Cone & 38.5 & 34.7 & 35.0 & 35.2 \\
$\quad$ Argentina & $\ldots$ & 20.0 & 21.1 & 20.4 \\
$\quad$ Chile & 19.1 & 42.8 & 44.5 & 44.6 \\
$\quad$ Uruguay & 38.7 & & & 15.8 \\
Andean & & 9.7 & 13.8 & 18.7 \\
$\quad$ Colombia & 9.2 & 16.0 & 16.8 & 25.0 \\
$\quad$ Venezuela & 14.4 & 26.4 & 25.2 & 32.4 \\
Caribbean & & 16.9 & 23.5 & 19.5 \\
$\quad$ Cuba & $\ldots$ & 23.7 & 39.0 & \\
$\quad$ Puerto Rico & $\ldots$ & 16.4 & 20.7 & \\
$\quad$ Trinidad \& Tobago & 29.3 & & & \\
Central America & & & & \\
$\quad$ Costa Rica & 13.9 & & & \\
\hline
\end{tabular}

Source: Pan American Health Organization, Technical Information System, 1999. 
FIGURE 2. Three-year moving average age-standardized cancer mortality rates in women aged 25 to 74 in low breast cancer mortality countries of the Americas, plus Puerto Rico, 1960-1994

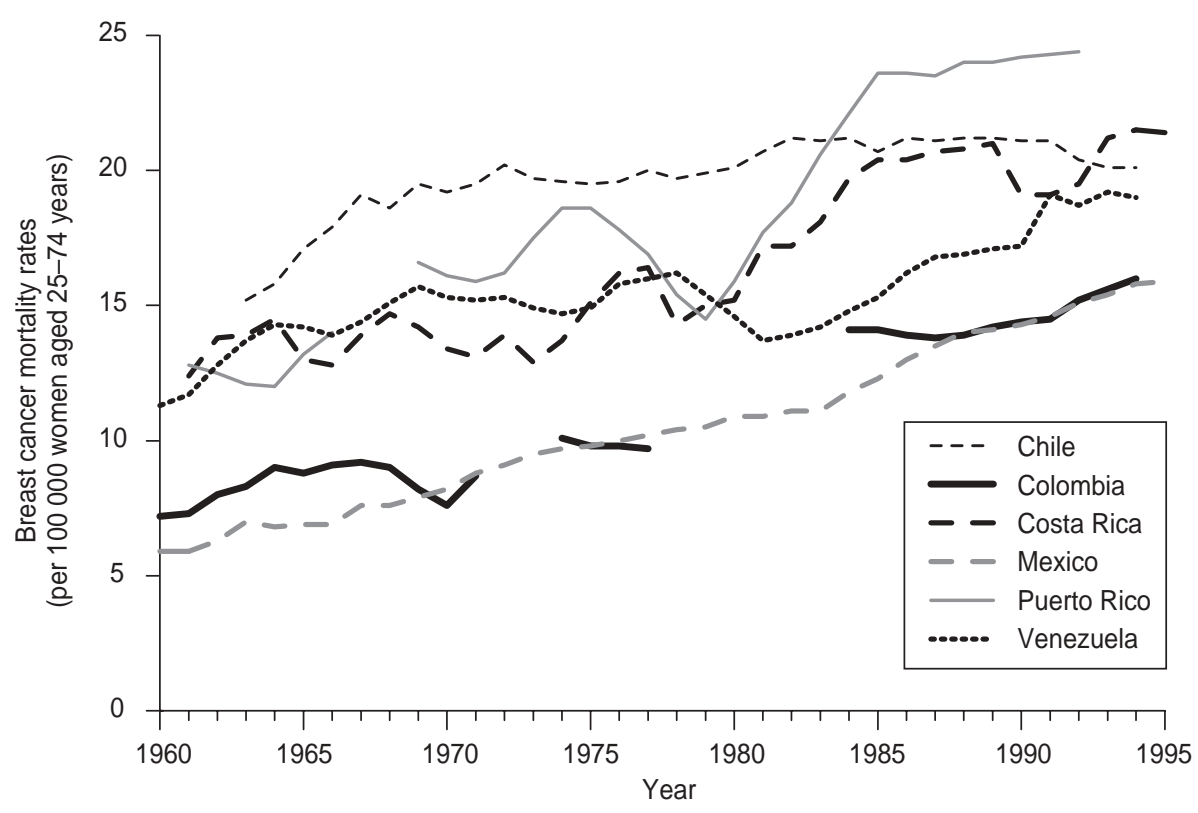

Note: Some lines have breaks or are incomplete due to missing data.

FIGURE 3. Three-year moving average age-standardized cancer mortality rates in women aged 25 to 74 in high breast cancer mortality countries of the Americas, 1960-1994
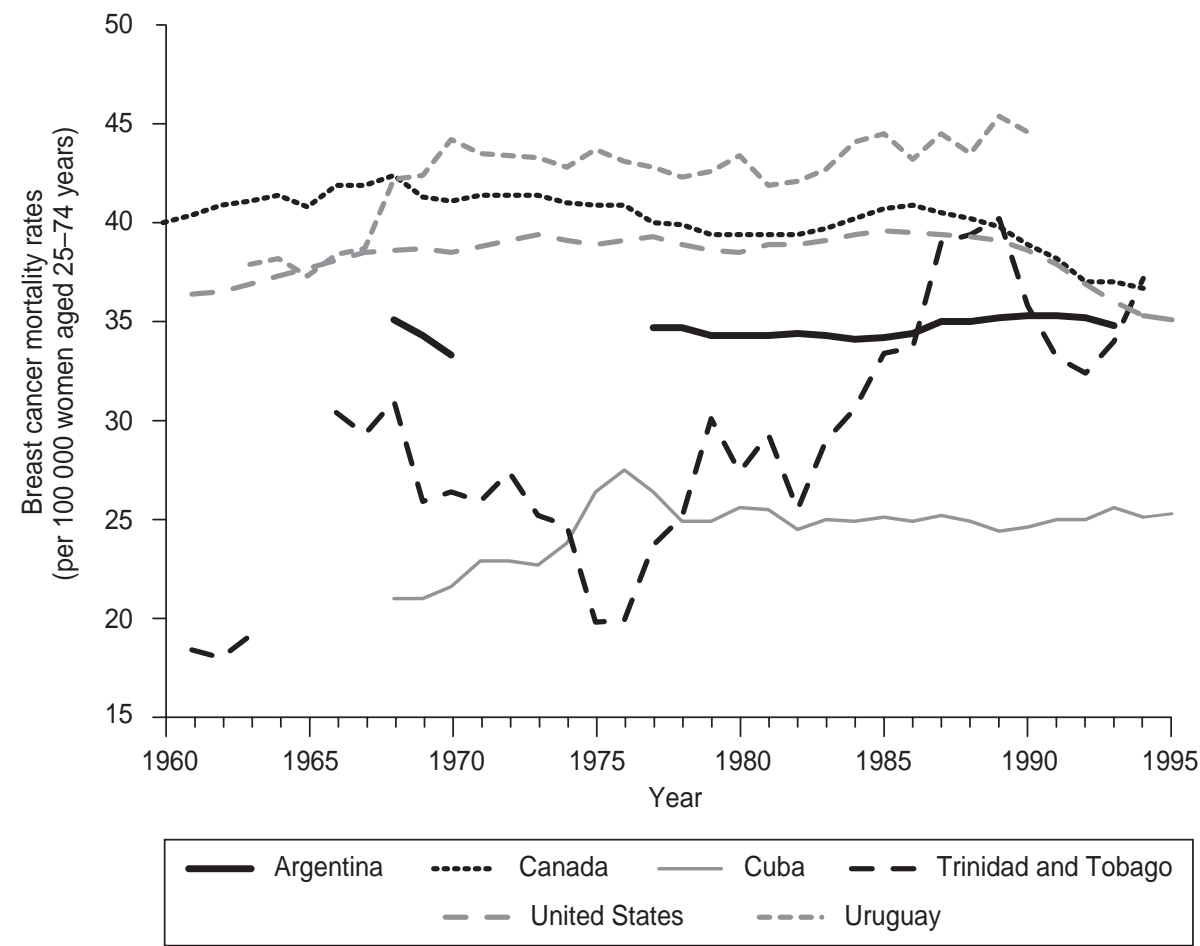

Note: Some lines have breaks or are incomplete due to missing data.
TABLE 2. Breast cancer mortality/incidence (M/l) ratio for selected countries in the Americas, plus Puerto Rico, 1988-1995

\begin{tabular}{lc}
\hline \multicolumn{1}{c}{ Country } & M/I ratio \\
\hline United States $^{\mathrm{a}}$ & 0.37 \\
Colombia & 0.40 \\
Costa Rica & 0.42 \\
Canada & 0.46 \\
Uruguay & 0.50 \\
Puerto Rico & 0.54 \\
Argentina & 0.58 \\
\hline
\end{tabular}

a The ratio for the United States of America does not include data for Puerto Rico.

$\mathrm{M} / \mathrm{I}$ ratio (0.37), and Argentina had the highest (0.58). Although the United States has one of the highest incidence rates, its low mortality rates indicate a more successful control of breast cancer. This is in contrast to countries with low incidence and higher mortality rates, suggesting that women in these countries come to the attention of health services at late stages of their disease.

Of the 24 countries to which we sent surveys asking about their breast cancer control activities, 21 of them responded, and Brazil, Jamaica, and Nicaragua did not answer. Of the 21 countries that responded, 11 of them sent information about their breast cancer screening policies (Table 3 ). The other 10 responded that they did not yet have a national initiative for breast cancer control; they were: Bahamas, Dominican Republic, El Salvador, Guatemala, Guyana, Haiti, Honduras, Paraguay, Peru, and Trinidad and Tobago.

In the 11 countries with screening policies, regardless of the resources they had available for health or the population who needed services, there was a wide variety of screening policies as well as differences in the target age groups (Table 3). Mammography, clinical breast examinations, and breast self-examinations were each recommended in nearly all of the countries. Chile is to introduce mammography in a second phase of its screening program. Clinical breast examination and breast self-examination were recom- 
TABLE 3. Screening policies recommended ("rec'd") in breast cancer control in selected countries of the Americas, as of April 2000

\begin{tabular}{|c|c|c|c|c|c|c|c|c|c|}
\hline \multirow[b]{2}{*}{ Country } & \multirow{2}{*}{$\begin{array}{l}\text { Health expenditure } \\
(\%)^{\mathrm{a}}\end{array}$} & \multicolumn{2}{|c|}{ Breast self-exam } & \multicolumn{3}{|c|}{ Clinical breast exam } & \multicolumn{3}{|c|}{ Mammography } \\
\hline & & Rec'd & Age & Rec'd & Age & Frequency & Rec'd & Age & Frequency \\
\hline Argentina & 9.7 & No & $N / A^{b}$ & Yes & $\begin{array}{l}50-70 \\
70-79\end{array}$ & $\begin{array}{l}\text { Yearly } \\
\ldots{ }^{c}\end{array}$ & Yes & $50-70$ & Every $2 \mathrm{yr}$ \\
\hline Bolivia & 6.5 & Yes & $15-75$ & Yes & $25-75$ & Yearly & Yes & $25-75$ & Every $2 \mathrm{yr}$ \\
\hline Chile & 7.9 & Yes & $35+$ & Yes & $35-64$ & Every 3 yr & Yes $^{d}$ & $50-64$ & Every $3 \mathrm{yr}$ \\
\hline Costa Rica & 8.5 & Yes & $\ldots$ & Yes & $35+$ & Yearly & Yes & $50-70$ & Every 2 yr \\
\hline Cuba & $N / A$ & Yes & $30+$ & Yes & $30+$ & Yearly & Yes & $\begin{array}{l}30-49 \\
50-65\end{array}$ & $\begin{array}{l}\text { Every } 2 \text { yr } \\
\text { Every } 2-3 \text { yr }\end{array}$ \\
\hline Ecuador & 5.3 & Yes & Teens+ & Yes & Teens+ & Yearly & Yes & $\begin{array}{c}40-49 \\
50+\end{array}$ & $\begin{array}{l}\text { Every } 2 \text { yr } \\
\text { Yearly }\end{array}$ \\
\hline Venezuela & 7.5 & Yes & $12-64$ & Yes & $35-74$ & Yearly & Yes & $\mathrm{HRT}^{\mathrm{e}}$ & $\ldots$ \\
\hline
\end{tabular}

mended for women of a wide and varying age range, beginning as early as adolescence, in Ecuador.

\section{DISCUSSION}

Breast cancer mortality has been increasing in most parts of Latin America and the Caribbean. Although incidence data were not available at the national level for the majority of the LAC countries, it can be assumed that the rising mortality rates are indicative of the risk of breast cancer. Availability of better diagnostic tests and increased reporting of breast cancer have probably contributed somewhat to the rising mortality rates that have been found. Nevertheless, there is no reason to believe that there has not been a real increase in the number of cases and deaths due to breast cancer, as has been observed in other countries that have gone through an epidemiologic transition.
In our mortality analysis we only included countries with less than $15 \%$ underregistration of deaths; therefore, this study is only a partial assessment of the situation in Latin America and the Caribbean. However, LAC countries not included have high fertility rates and thus it is likely that their breast cancer incidence is low. Although we did not include all of the English-speaking Caribbean countries, the high mortality rates in Trinidad and Tobago suggest that breast cancer may be a problem in this subregion of the Americas. In addition, clinical studies conducted at the University Hospital of the West Indies, in Kingston, Jamaica, show problems with the diagnosis and treatment of the disease, thus indicating a need to further explore the situation (5).

Although breast cancer has been studied for decades, it is only recently that its causes are beginning to be understood. Reproductive factors, such as nulliparity, early menarche, late menopause, and late age at first birth have been established as causative risk factors, along with genetic background (6). Unfortunately, primary prevention is very difficult for this set of risk factors. Prevention may be possible for other risk factors such as the use of oral contraception and long-term hormone replacement, postmenopausal obesity, and exposure to ionizing radiation. However, the attributable risk of the latter set of factors is relatively low. According to Madigan and colleagues (6), $41 \%$ of breast cancer cases in the United States are attributable, in order, to mother's age at first birth after the age of 20, nulliparity, family history of breast cancer in a first-degree relative, and high family income. In another study, Bruzzi et al. (7) calculated an attributable risk of $55 \%$ for the combination of early age at menarche, age at first birth after age 20, more than two previous breast biopsies, and a family history of breast cancer. With regards to developing countries, much less 
work has been undertaken. Nevertheless, Colditz (8) has shown that up to $50 \%$ of international variations in breast cancer incidence can be explained by differences in childbearing practices, a finding that supports the relationship between total fertility rates and breast cancer incidence presented in this paper.

In terms of secondary prevention, mammography for women 50-69 years old is the only screening method that has been shown to reduce mortality, by $23 \%$ according to a meta-analysis of eight randomized trials $(9,10)$.

Mammography screening for women under 50 years old is much more controversial. In fact, meta-analyses of the mammography trials with follow-up of less than 10 years mostly show no protective effect for mammography. However, later meta-analyses, where mammography was conducted in women aged 40-49 initially and who were followed for 10-18 years did show an $18 \%$ reduced mortality $(95 \%$ confidence interval of $5 \%-29 \%$ ) (11). A Swedish study also reported reduced mortality for women ages 40-49 (12). After 10-18 years of follow-up, women entering the trials at age $40-49$ years are 50-67 years old. As no benefit is seen prior to 10 years of follow-up, the observed benefit of mammography for this younger group of women may be partly, if not totally, due to screening after the age of 49. Age migration should be considered as an explanation for this delayed benefit. Some industrialized countries recommend against mammography screening in women 40-49 years old, whereas others recommend that women and physicians make decisions on a case-by-case basis.

Due to the lower incidence of breast cancer among women 40-49 years old, it has been estimated that 2500 women in their forties would need to be screened every year for 10 years to prevent one breast cancer death, whereas only 270 women ages 50-69 would need to be screened every two years for 20 years to prevent one death (9). Along the same lines, in countries with low incidence rates, such as Costa Rica, Chile, Colombia, Mexico, and
Venezuela, approximately 3000 women in their fifties would need to be screened every two years for 20 years to prevent one cancer death. Clearly, from the point of view of costeffectiveness, screening with mammography is not justified in women under 50 in most Latin American countries. However, mammography screening for women aged 50-69 may warrant consideration in Uruguay, Argentina, and Trinidad and Tobago, where rates are relatively high, but only if resources are available. Nonetheless, Bolivia, Chile, Cuba, Ecuador, Mexico, and Panama offer mammography within their health care systems, including to women as young as 25 years of age. Information on how mammography is offered in private sector settings in Latin America and the Caribbean is not available, but it is likely that only women of high socioeconomic status would have access to these services. Neither is there published information on quality assurance, as there should be for any screening service.

A second method of breast cancer screening is the clinical breast exam (CBE), conducted periodically by a health care professional. There is no direct evidence assessing the effect of CBE in comparison to no screening or to mammography. There is conflicting evidence from randomized controlled trials, case-control studies, and metaanalyses as to the added benefit of CBE used in combination with mammography and to mammography used to enhance CBE detection rates (13-15). The sensitivity of $\mathrm{CBE}$ in detecting a malignant tumor is lower than that of mammography, although the number of false positives detected is also slightly lower (16). Clearly, more information is needed, and a proper trial is warranted. Nonetheless, all 11 LAC countries with screening policies reported that $\mathrm{CBE}$ is being promoted as a screening method. CBE is recommended for women in their twenties in 5 of those countries.

Breast self-examination (BSE) is based on the notion that up to $90 \%$ of all breast cancers are detected by women themselves (17). It has been argued that a more systematic approach to self-examination could lead to earlier detection. Nevertheless, preliminary evidence from two randomized clinical trials, one conducted in Shanghai, China, (18) and the other in St. Petersburg, Russia, (19), has shown no difference in mortality between women who practiced BSE regularly and those who did not.

The argument has been made that in spite of the lack of clear evidence of the effectiveness of BSE, it may be useful to teach and promote BSE in developing countries because it will raise awareness of breast cancer and do so at a low cost. Hence, women may come to the attention of health services at an earlier stage of the disease. However, two issues should be considered. First, teaching and promoting BSE has a cost that may not be offset by gains made through early detection; the lack of specificity of BSE means that many more benign breast lumps will be detected and will need follow-up imaging and biopsies. Second, even if women approach public health services for their breast lumps, the health care system may not have adequate diagnostic or treatment capabilities, including the appropriate technology, to assess or manage all the women. Or, the women may have to bear the cost of follow-up themselves.

These variations in recommendations reflect a poor use of current scientific evidence, either because the evidence is not available to the national policymakers or because there is no culture of considering evidence in their decision-making. Language may also be a barrier, since most relevant literature is published in English. In addition, there is a level of difficulty in interpreting the results of studies that use sophisticated methods of analysis. Therefore, efforts should be made to summarize and provide this information in the local language as well as to help policymakers to appropriately weigh the evidence.

Qualitative studies have found that women in middle and late adulthood in Latin America are not aware of the 
benefits of preventive health practices, as has been reported in a series of studies summarized in a special PAHO report (20). These women use health services primarily during their childbearing years such as for prenatal care, family planning, and pediatric services. Given this situation, it is important to raise women's awareness of their risk of breast cancer such as during those health care visits and at women's groups' meetings. Women's needs in relation to breast cancer must be assessed, and local capacity must be built to address those needs. The needs are likely to include information, screening clinics, and treatment. However, there may be many more barriers that will have to be addressed: Is local capacity present? Are financial, technological, and human resources available to answer the needs? Can the service be offered to all women, not only those with private health insurance? Have standards and guidelines been developed? Are health care providers following recommended standards for diagnosis and treatment?

There is still much controversy over breast cancer screening methods, in particular their cost-effectiveness and positive predictive value in countries with low prevalence of disease. However, there is increasing evidence of the efficacy and cost-effectiveness of treatment in early stages of the disease (21). In view of the increasing incidence of breast cancer in developing countries, it is crucial that women and health personnel alike have access to relevant and current information on breast cancer risk, screening methods, and current treatment practices. At the same time, further research is necessary to better understand how to reach and involve women in preventive practices in different cultural settings.

\section{REFERENCES}

1. Pan American Health Organization. Health in the Americas, 1998 edition. Volume I. Washington D.C.: PAHO; 1998. (PAHO Scientific Publication No. 569).

2. Pan American Health Organization. Health statistics in the Americas. Washington, D.C.: PAHO; 1998. (PAHO Scientific Publication No. 567).

3. Parkin DM, Whelan SL, Ferlay J, Raymond I, Young J, eds. Cancer incidence in five continents, volume VII. Lyon, France: International Agency for Research on Cancer; 1997. (IARC Scientific Publication No. 143).

4. Coleman M, Estève J, Damiecki P, Arslan A, Renard $\mathrm{H}$, eds. Trends in cancer incidence and mortality. Lyon, France: International Agency for Research on Cancer; 1993. (IARC Scientific Publication No. 121).

5. Walters JP. Outcome of stage I carcinoma of the breast at the University Hospital of the West Indies (1982-1988). West Indian Med J 1994;43(4):127-129.

6. Madigan MP, Ziegler RG, Benichou J, Byrne C, Hoover RN. Proportion of breast cancer cases in the United States explained by wellestablished risk factors. J Nat Cancer Inst 1995; 87(22):1681-1685.

7. Bruzzi P, Green SB, Byar DP, Brinton LA, Schairer C. Estimating the population attributable risk for multiple risk factors using case-control data. Am J Epidemiol 1985;122: 904-914.

8. Colditz GA. A biomathematical model of breast cancer incidence: the contribution of reproductive factors to variation in breast cancer incidence. In: Fortner JG, Sharp PA, eds.
Accomplishments in cancer research 1996. Philadelphia, Pennsylvania, United States: Lippincott-Raven; 1997. Pp. 116-121.

9. Frisell J, Lidbrink E, Hellstrom L, Rutqvist LE. Followup after 11 years-update of mortality results in the Stockholm mammographic screening trial. Breast Cancer Res Treat 1997; 45(3):263-270

10. Kerlikowske K. Efficacy of screening mammography among women aged 40 to 49 and 50 to 69 years: comparison of relative and absolute benefit. J Natl Cancer Inst Monogr 1997;(22):79-86.

11. Hendrick RE, Smith RA, Rutledge III JH, Sment CR. Benefit of screening mammography in women aged 40-49: a new meta-analysis of randomized controlled trials. J Natl Cancer Inst Monogr 1997;(22):87-92.

12. Andersson I, Janzon L. Reduced breast cancer mortality in women under 50: updated results from the Malmo Mammographic Screening Program. J Natl Cancer Inst Monogr 1997;(22): 63-67.

13. Miller AB, Baines CS, To T, Wall C. Canadian National Breast Cancer Screening Study: 2. Breast cancer detection and death rates among women aged 50 to 59 years. CMAJ 1992;147 (10):1477-1488.

14. Kerlikowske K, Grady D, Rubin SM, Sandrock C, Ernster VL. Efficacy of screening mammography: a meta-analysis. JAMA 1995;273 (2):149-154.

15. Barton MB, Harris R, Fletcher SW. Does this patient have breast cancer? The screening clinical breast examination: should it be done? How? JAMA 1999;282(13):1270-1280.
16. Elmore JG, Barton MB, Moceri VM, Polk S, Arena PJ, Fletcher SW. Ten-year false positive screening mammograms and clinical breast examinations. N Engl J Med 1998;338(18): 1089-1096.

17. Giuliano AE. Breast. In: Tierney LM, McPhee SJ, Papadakis MA, eds. Current medical diagnosis \& treatment. 35th ed. Stamford, Connecticut, United States of America: Appleton \& Lange; 1996. Pp. 617-636.

18. Thomas DB, Gao DL, Self SG, Allison CJ, Tao Y, Mahloch J, et al. Randomized trial of breast self-examination in Shanghai: methodology and preliminary results. J Natl Cancer Inst 1997;89:355-365.

19. Semiglazov VF, Moiseyenko VM, Bavli JL, Migmanova NSh, Seleznyov NK, Popova RT, et al. Role of breast self examination in early detection of breast cancer: Russia/WHO prospective randomized trial in St. Petersburg. Cancer Strategy 1999;1:145-151.

20. Pan American Health Organization, Program on Non-communicable Diseases. Preventive practices among women: bridging the gap. Washington D.C.: PAHO; 2001.

21. Nuffield Institute for Health, University of Leeds; NHS Centre for Reviews and Dissemination, University of York. The management of primary breast cancer. Effective Healthcare 1996;2(6):1-16.

Manuscript received 17 May 2001. Revised version accepted for publication 21 February 2002. 
RESUMEN Hace tan solo dos décadas, el cáncer de mama no se consideraba un problema de salud pública importante en América Latina y el Caribe (ALC). Sin embargo, las tasas de mortalidad del cáncer de mama han estado en aumento durante al menos 40 años en la mayoría de los países de ALC. Se cree que el desarrollo socioeconómico y los consiguientes cambios de los comportamientos reproductivos a lo largo de los últimos 50 años han contribuido a aumentar el riesgo de cáncer de mama. Ese mismo desarrollo socioeconómico ha aumentado también los conocimientos de la mujer sobre la salud y, por consiguiente, la demanda de servicios de calidad. En los países industrializados se están poniendo en práctica el tamizaje y protocolos terapéuticos de gran calidad como principal estrategia para controlar el cáncer de mama. Los estudios realizados demuestran que, de los tres métodos de tamizaje existentes (mamografía, examen clínico de la mama y autoexploración de la mama), solo la mamografía en mujeres de 50 a 69 años ha sido eficaz para reducir la mortalidad, en un $23 \%$, según las estimaciones. Aunque hay mucha controversia acerca de los beneficios y de la relación costo-efectividad del tamizaje mamográfico en mujeres de 40 a 49 años, en algunos países, como Australia, los Estados Unidos de América y cuatro países europeos, se recomienda que los médicos valoren su necesidad en cada caso. Una encuesta que hemos realizado en países de ALC muestra que la mayoría de sus políticas de detección del cáncer de mama no están justificadas por las pruebas científicas disponibles. Además, como demuestran las razones relativamente elevadas entre la mortalidad y la incidencia, los casos de cáncer de mama no están siendo tratados adecuadamente en muchos países de ALC. Antes de seguir desarrollando programas de detección, estos países necesitan evaluar la factibilidad de diseñar y poner en práctica normas terapéuticas adecuadas y de proporcionar un amplio acceso a los servicios diagnósticos y terapéuticos. Dada la importancia actual del cáncer de mama en ALC, es esencial que tanto las mujeres como los profesionales sanitarios tengan acceso a información actualizada sobre la cual basar sus decisiones.

\title{
International Society for Equity in Health Second International Conference
}

\author{
Dates: $\quad$ 14-16 June 2002 \\ Location: University of Toronto \\ Toronto, Ontario, Canada
}

The theme of the Second International Conference of the International Society for Equity in Health (ISEqH) is "Equity: Research in the Service of Policy and Advocacy for Health and Health Services."

The meeting will feature a number of presentations as well as a keynote speech by Lucy Gilson, from South Africa. There will also be workshops on various topics, including on writing for publication.

The cost of registration for the meeting for persons who are not ISEqH members is US\$ 228 if paid by 15 April 2002; the fee is US\$ 260 after that date. Lower fees are available for ISEqH members and for students.

\author{
Information: \\ ISEqH Secretariat \\ 620 University Avenue, 8th Hoor \\ Toronto, Ontario M5G2C1, Canada \\ Telephone: (416) 978-3763 \\ Fax: (416) 978-3912 \\ E-mail: iseqh.exec@utoronto.ca \\ Web site: http://www.iseqh.org
}

